\title{
Evaluation of school-based prevention program in Turkey: Results of a 24-month study
}

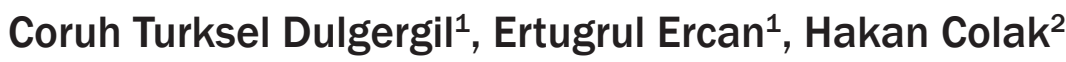

Correspondence: Dr. Coruh Turksel Dulgergil

Email: dulgergil@hotmail.com

\begin{abstract}
'Department of Restorative Dentistry, Kirikkale University School of Dentistry, Kirikkale, Turkiye, ${ }^{2}$ Department of Restorative Dentistry, Zirve University School of Dentistry, Gaziantep, Turkiye
\end{abstract}

\section{ABSTRACT}

Objective: In this paper, cavity experiences of children with different levels of eruption and cavity activities that are enrolled at an elementary school with semi-rural characteristics in Kırıkkale Provincial center were monitored for 2 years after a variety of protective applications. Materials and Methods: Three hundred and twenty-two children at the age of 7-11 were included in this study. Children were grouped as follows according to their cavity experiences and applications done: Group 1 - control group (with or without cavities) - was given hygiene training only; Group 2 - with medium level cavity activity (2-4 cavities in average) - oral hygiene training + surface restoration applied; Group 3 - children with 2-4 cavities on average - oral hygiene training + professional flour gel applied; Group 4 - children with 2-4 cavities in average - oral hygiene training + flour gel applied with brush; Group 5 - children with extreme cavity activity (children with 5 or more cavities) - oral hygiene training + surface restoration + professional flour gel combination applied. Results: At the end of the $2^{\text {nd }}$ year, 277 children were reached. The increase of number of cavities in permanent teeth was determined as $35 \%, 0 \%, 1 \%, 0 \%$, and $7 \%$ in groups $1-5$, respectively. The difference between groups was found to be significant (Chi-square analysis, Pearson Chi-square $=27.002, P<0.01$ ). Conclusion: These findings have showed that, in Kirlkkale Provincial center, some cavity-preventive measures such as surface restoration and gel applications, along with hygiene training, could provide optimum protection for school-age children.

Key words: Atraumatic restorative treatment surface restoration, flour gel, gel application with brush, protective measures, tooth cavity

\section{INTRODUCTION}

Growth-development disorders, which can be prevented by education at schooling age, include tooth cavities and epidemics. Tooth cavities are generally ignored as they are not seen as that life-threatening. However, oral and tooth health is an important part of health in general, vital functions, and living quality. According to the 2002 Ministry of Health reports, three most common diseases in elementary school children at 6-12 ages are tooth cavities, throat infections, and intestinal parasites. ${ }^{[1]}$

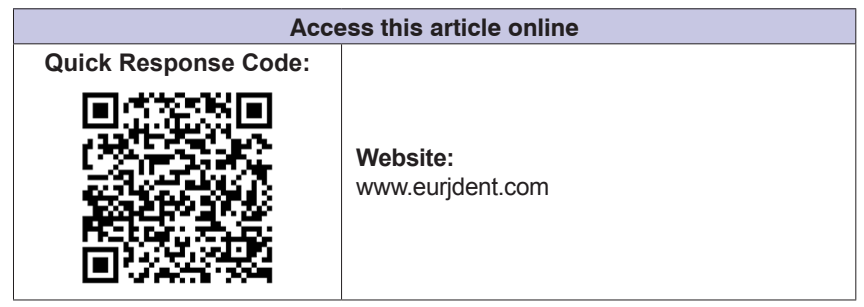

In most developed countries, decrease in tooth cavities in the last three decades are attributed to several factors such as usage of fluoride toothpastes, as well as control of sugar consumption, improvement of socioeconomic status, widening of dentistry services, and improvement in the awareness of personal hygiene applications. ${ }^{[2]}$ Nevertheless, according to the latest epidemiological study conducted in our country, cavity is still a public health problem at the ages of 5 and 12 . In this study, cavity prevalence for

This is an open access article distributed under the terms of the Creative Commons Attribution-NonCommercial-ShareAlike 3.0 License, which allows others to remix, tweak, and build upon the work non-commercially, as long as the author is credited and the new creations are licensed under the identical terms.

For reprints contact: reprints@medknow.com

How to cite this article: Dulgergil CT, Ercan E, Colak H. Evaluation of school-based prevention program in Turkey: Results of a 24-month study. Eur J Dent 2016;10:245-9.

DOI: $10.4103 / 1305-7456.178312$ 
the ages of 5 and 12 was reported as $46.9 \%$, decayed, missing, and filled teeth (dmft) 1.99 and $61.1 \%$, dmft 1.9 , respectively.

In our country, tooth cavities are especially most important problems for school-age children; however, there is no systematic and national protective application for its prevention. Therefore, 24 of 100 children at the age of 9 in our country have one permanent grinder tooth affected or lost by cavities. ${ }^{[3]}$ Although prevention or decrease seems more practical and economic when compared to treatment of tooth cavities, the problem is related to the frequency and pattern of application of the system (whichever it is).

In this study, the effect of oral hygiene training, professional topical fluoride, atraumatic restorative treatment (ART)-fissure restoration, and brush-on fluoride application combinations impacts on cavity formations and dmft for a 24-month period on a group of elementary school students, which could provide a model for semi-rural areas of Central Anatolia. The null hypothesis tested was that supervised brush-on fluoride gel application could be effective way to prevent caries occurrence in children.

\section{MATERIALS AND METHODS}

Three hundred twenty-two children in 7-11 age group enrolled at İsmail Ustüner Elementary School (Karşıyaka District) under the jurisdiction of Kirıkkale Provincial Directorate of National Education were included in this study. The research was conducted upon report of Ethical Board of Kirikkale University Faculty of Dentistry and permissions given by Governor's Office and Kırıkkale Provincial Directorate of National Education. First, an 8-week long oral health training was given to everybody who would be subjected to the study at the research school. After this training process, students were examined and grouped into the following categories according to their cavity situations:

- Group 1: Control group; children with no cavities or less cavities (one cavity or none): Received only oral hygiene training

- Group 2: Children with medium level of cavities (2-4 cavities on average): Received oral hygiene training and surface restoration were applied with ART method. During this application, all primary molars were restored with a high-resistant glass ionomer mixed to fluid thickness (Ketac-Molar,
3M/ESPE Dental Products, St. Paul, MN, USA)

- Group 3: Students on whom brush-on fluoride gel is applied. On this group, brush-on fluoride gel was applied by class teachers 4 times a year (Voco Profluorid Gelee-2000 ppm-VOCO Gmbh-Cuxhaven, Almanya)

- Group 4: The group on which professional fluoride gel was applied; twice a year gel application with trey in class conditions after tooth isolation (Fluoridine N-5, VOCO Gmbh-Cuxhaven, Germany)

- Group 5: Children with extreme cavity activity (5 or more cavities); along with oral hygiene, a combination of ART-surface restoration and professional fluoride gel (Fluoridine N-5) was applied.

All operations were conducted in school conditions and according to World Health Organization's (WHO) rules. Treatable permanent tooth cavities of children in all groups were treated in school conditions by using ART hand-tools and high-resistant glass-ionomer dental cements (Ketac-Molar, 3M/ESPE Dental Products, St. Paul, MN, USA).

All examinations were performed by two experienced researchers (ÇTD, EE) at the beginning of the study and in the $24^{\text {th }}$ month. To provide consistency between researchers in terms of cavity existence and WHO treatment criteria, interexaminer reliability study was performed on groups of 20 children against all treatment criteria. Possible kappa values of this study were determined as 0.90 and 0.80 .

\section{RESULTS}

The average age of the 322 children studied was determined as $8.87 \pm 1.36$ (age interval 7-11). Of the studied children, 154 were girls (48\%) and 168 were boys $(52 \%)$. Cavity prevalence (frequency, $n: 200$ ) was determined as $62.4 \%, \mathrm{df}(\mathrm{t}): 1.9 ; \mathrm{DMF}(\mathrm{T}) 0.23$ was decayed, missing, filled surface found as 0.47 . Only 9 of the children examined at the beginning were found to have 20 dental cements in total [Table 1].

Distribution into groups of children reached at the beginning, in the $1^{\text {st }}$ year and $2^{\text {nd }}$ year is shown in Table 2. Children with new cavity formations in permanent teeth at the end of the $2^{\text {nd }}$ year are shown in Table 3 according to the groups.

During the research, 43 ART restorations and 103 ART surface restorations were applied to 61 children in total. Forty-one of the 43 ART restorations reached 
at the end of the $1^{\text {st }}$ year were not lost (95\%); of the 99 ART surface restorations, 50 were completely present, 21 were partially present, and 28 were lost. In brush-on gel group, gel was applied at least 2-4 times a year; in professional gel groups, gel was applied twice a year.

At the end of the $2^{\text {nd }}$ year, comparison was made in terms of the children who developed new cavities (in their permanent or deciduous teeth) [Tables 3 and 4]. New cavity formation was observed in $35 \%$, $0 \%, 1 \%, 0 \%$, and $7 \%$ of deciduous teeth of children at Group 1 (control group), Group 2 (ART-surface restoration group), Group 3 (brush-on gel group), Group 4 (professional gel group), and Group 5 (surface restoration-fluoride gel group), respectively. When the groups were compared based on Chi-square analysis (Pearson Chi-square $=27,002$ ), significant difference between groups was found $(P<0.01)$. Accordingly, significant cavity increase was determined in control group, which was found significantly higher than other groups. This group was followed by the group which had highest cavity activity (ART-fissure sealants + professional fluoride gel). Difference between other groups was not found statistically significant.

Permanent cavity formation percentages of children controlled at the end of $2^{\text {nd }}$ year were found as $0 \%, 0 \%$, $7 \%, 0 \%$, and $7 \%$ in groups $1,2,3,4$, and 5 , respectively, and difference between the groups was not found statistically significant (Chi-square analysis, Pearson Chi-square $=7669, P>0.05)$.

\begin{tabular}{lc}
$\begin{array}{l}\text { Table 1: Distribution into groups of the children } \\
\text { examined at the beginning }\end{array}$ \\
\hline Ismail Ustüner primary education school & $\boldsymbol{n}$ (children) \\
\hline 7 & 65 \\
8 & 72 \\
9 & 75 \\
10 & 56 \\
11 & 54 \\
Gender & \\
Female & 155 \\
Male & 167 \\
Total & 322 \\
\hline
\end{tabular}

\section{DISCUSSION}

Usage of brush and fluoride toothpaste is seen as the cause of decrease in tooth cavities in most European countries. ${ }^{[4]}$ Nevertheless, oral hygiene may not be sufficient for preventing new cavities in, especially cavity active totals. School-age children are at risk due to undeveloped hygiene habits, eating habits, and inadequate dental maturity (reference). Therefore, many developing countries launched school-based oral health training and protective application programs in the last three decades. Programs launched in Indonesia, Brazil, and Madagascar in the last decade yielded very encouraging results. ${ }^{[5-7]}$ One of the most prominent results obtained in such countries is oral health training program conducted in Wuhan, China, by WHO and Copenhagen University. ${ }^{[8]}$ In this program, which was based on class teacher knowledge and habits and indirect mother training basically, significant achievements were made in a 3-year period. This research once again emphasized the importance of school environment for both health education and protective applications, as well as the determinant role of class teacher training. In this respect, as a first step, teacher trainings were completed in our study and its later benefits were monitored.

Cavity-preventive methods can be summarized in general as usage of fluorides of different forms, improvement of oral hygiene and control of sugar consumption. ${ }^{[9]}$ According to the findings of the present study, supervised brush-on fluoride gel application found effective in terms of caries prevention. Therefore, hypothesis tested was accepted. In our study, gel form of fluoride was applied in classroom environment both with professional method and kids' toothbrush; therefore, contact of children with fluoride was ensured with a practical application. Another benefit of applying brush-on fluoride is that it introduces toothbrush to the children. Keeping the toothbrush in backpack during the training and its application at least once every day under teacher control provided an opportunity for earning the children the habit of tooth-brushing. The third break, which is also lunch break, for brushing in class environment, was teachers'

\begin{tabular}{l} 
Table 2: Distribution into groups of children reached at the beginning, in the $\mathbf{1}^{\text {st }}$ year and $2^{\text {nd }}$ year \\
\hline
\end{tabular}




\begin{tabular}{|c|c|c|c|c|}
\hline $\begin{array}{l}\text { Control } \\
\text { group } \\
\text { ( } n=\text { Children) } \\
(\%)\end{array}$ & $\begin{array}{l}\text { ART- } \\
\text { fissure } \\
\text { sealant } \\
(\%)\end{array}$ & $\begin{array}{c}\text { Brush } \\
\text { fluoride } \\
\text { gel }(\%)\end{array}$ & $\begin{array}{l}\text { Professional- } \\
\text { fluoride gel } \\
(\%)\end{array}$ & $\begin{array}{l}\text { Fissure } \\
\text { sealant- } \\
\text { fluoride } \\
\text { gel }(\%)\end{array}$ \\
\hline 155 & 23 & 31 & 60 & 8 \\
\hline$\triangle \mathrm{DMFT}: 0.03$ & $\triangle \mathrm{DMFT}: 0.0$ & $\triangle \mathrm{DMFT}: 0.0$ & $\triangle \mathrm{DMFT}: 0.06$ & $\triangle \mathrm{DMFT}: 0.0$ \\
\hline $2^{*}(1.3)$ & $0^{*}(0)$ & $0 *(0)$ & $4^{*}(6.6)$ & $0^{*}(0)$ \\
\hline
\end{tabular}

\begin{tabular}{|c|c|c|c|c|}
\hline $\begin{array}{l}\text { Control } \\
\text { group } \\
\text { ( } n=\text { New } \\
\text { caries) }\end{array}$ & $\begin{array}{l}\text { ART- } \\
\text { fissure } \\
\text { sealant }\end{array}$ & $\begin{array}{l}\text { Brush } \\
\text { fluoride } \\
\text { gel }\end{array}$ & $\begin{array}{l}\text { Professional- } \\
\text { fluoride gel }\end{array}$ & $\begin{array}{c}\text { Fissure } \\
\text { sealant- } \\
\text { fluoride } \\
\text { gel }\end{array}$ \\
\hline 155 & 23 & 31 & 60 & 8 \\
\hline$\Delta \mathrm{dmft}: 0.6$ & $\Delta \mathrm{dmft}: 0.0$ & $\Delta \mathrm{dmft}: 0.0$ & $\Delta \mathrm{dmft}: 0.08$ & $\Delta \mathrm{dmft}: 0.0$ \\
\hline
\end{tabular}

ART: Atraumatic restorative treatment, dmft: Decayed, missing, and filled teeth

choice. This timing, which aimed to decrease, even a little bit, of cavity-forming effects of the sweet foods brought from home or bought from the canteen in an uncontrolled manner, is essential. Of the three basic concepts listed above, which were fluoride application, brush training, and decrease of sugar consumption, two were achieved in school environment, but the problem with sugar remains unsolved. This case will be an important anecdote which has to be discussed in the further stages of our research; it also should have reflections on school canteens.

Contrary to the expectations of our country, in industrialized countries, almost all of childhood protective applications are performed either by family dentists or by public health dental polyclinics under the control of municipalities. Almost all of these applications are not made by dentists, but by dental assistants, who receive 2 years of training. In this respect, our country presents a marked case of deadlock both in terms of application method and management and lack of implementers. This is the reason why brush-on fluoride gel application was made by class teachers in our study, and its functionality was tested as well. Although not discussed in our findings, it is understood that brush-on fluoride gel application can easily be performed by class mothers or another mature person. Brush-on fluoride gel application is new for or country, but it is successfully applied in many countries, especially in Switzerland. At the end of an 8-year research, it was found out that brush-on fluoride application, supported by other applications in school environment, leads to $60 \%$ decrease in cavities and 1-year process, $60 \%$ of children had less need for dental treatment. ${ }^{[10]} \mathrm{A}$ similar finding was reported by Marthaler. ${ }^{[1]}$ The decrease in cavities obtained in our study in brush-on fluoride gel group during 2-year term is in agreement with these studies. Nevertheless, when compared with FS group in our study, lower protection was obtained with F-gel. This case is parallel to the findings of Ripa et al. ${ }^{[12]}$ and Lewis et al., ${ }^{[13]}$ who claim that medium-level advantage could be achieved with annual 2 applications in 2-4 year period. On the other hand, it also supports findings of Selwitz et al. ${ }^{[14]}$ who compared different fluoride protocols in a 4-year field research with FS in a different design. At the end of 4-year period, researchers found that pit and fissure restorers provided a much more superior protection than fluoride protocols applied individually. This finding was supported by Songpaisan et al. based on a study conducted in Thailand; when compared with control group in 7-8 age groups, it was seen that glass ionomer fissure restorers provided better protection than fluoride gel. ${ }^{[15]}$ Fissure restorers are still one of the leading cavity-prevention methods widely used with fluoride preparations. Fissure restorers with glass-ionomer-based chemical hardening feature applied in recent years in field conditions displayed a better cavity prevention performance compared with antiresins. ${ }^{[16]}$ In field conditions where isolation control is difficult, using a material less affected by humidity gives significant advantage. For this reason, in our study, ART method and glass ionomer restorers were applied for surface restoration applications performed in school environment. Applied since the 1990s, ART, which is supported by WHO, proved to be a hopeful method in oral and dental health of children in developing countries. This technique, with no obligation for patients for clinical treatment, has some advantages such as cost, simplicity, and lack of pain compared to the conventional method, and it proved its validity as a protective method recently (surface restorative applications).

\section{CONCLUSION}

It was understood that, at elementary school age, when permanent eruption begins and when effort is paid to earn the children school discipline, a systematic oral dental health protective application for 2-3 years could work under local conditions in medium-size Anatolian cities.

It was found out that:

- When the facilities in a provincial center were used rationally, a systematic protective application 
could be achieved in a decentralized manner

- A simple method which attracts the attention of class teacher could create a tradition for oral-dental health

- Despite all problems caused by guardians and hygienic issues, brushing in class could be performed and for this, class teacher should be persuaded

- ART could have an important role as an auxiliary treatment method and in particular, young permanent molars could be earned significant time until the appointment time in dental treatment centers which have intense appointment programs.

\section{Financial support and sponsorship}

Nil.

\section{Conflicts of interest}

There are no conflicts of interest.

\section{REFERENCES}

1. Ministry of Health of Turkey Report. 2002. Ankara, Turkiye.

2. Tinanoff N, Palmer CA. Dietary determinants of dental caries and dietary recommendations for preschool children. J Public Health Dent 2000;60:197-206.

3. Doğan G, Gökalp S, Tekçiçek M, Berberoğlu A, Ünlüer Ş. The oral health profile of 5, 12 and 15 year olds, Turkey-2004. Clinical Dentistry and Resarch 2007;31:3-10.

4. Beltrán-Aguilar ED, Estupiñán-Day S, Báez R. Analysis of prevalence and trends of dental caries in the Americas between the 1970s and 1990s. Int Dent J 1999;49:322-9.

5. van Palenstein Helderman W, Mikx F, Begum A, Adyatmaka A,
Bajracharya M, Kikwilu E, et al. Integrating oral health into primary health care - Experiences in Bangladesh, Indonesia, Nepal and Tanzania. Int Dent J 1999:49:240-8.

6. Iwakura ML, Morita MC. Fluoride mouth-rinsing to prevent dental caries in a Brazilian municipality with fluoridated drinking water. Rev Panam Salud Publica 2004;15:256-61.

7. Petersen PE. The World Oral Health Report 2003: Continuous improvement of oral health in the $21^{\text {st }}$ century - The approach of the WHO Global Oral Health Programme. Community Dent Oral Epidemiol 2003;31 Suppl 1:3-23.

8. Petersen PE, Peng B, Tai B, Bian Z, Fan M. Effect of a school-based oral health education programme in Wuhan city, peoples republic of China. Int Dent J 2004;54:33-41.

9. Anderson MH, Bales DJ, Omnell KA. Modern management of dental caries: The cutting edge is not the dental bur. J Am Dent Assoc 1993;124:36-44.

10. Ferrazzini G. Prevention in the schools of Massagno, Ticino: Results after 8 years. SSO Schweiz Monatsschr Zahnheilkd 1979;89:147-50.

11. Marthaler TM. Interim report on DMF-reduction 16 years after the introduction of a preventive program. Community Dent Oral Epidemiol 1981;9:210-4.

12. Ripa LW, Leske GS, Forte F. The combined use of pit and fissure sealants and fluoride mouthrinsing in second and third grade children: One-year clinical results. Pediatr Dent 1986;8:158-62.

13. Lewis CW, Johnston BD, Linsenmeyar KA, Williams A, Mouradian W. Preventive dental care for children in the United States: A national perspective. Pediatrics 2007;119:e544-53.

14. Selwitz RH, Nowjack-Raymer R, Driscoll WS, Li SH. Evaluation after 4 years of the combined use of fluoride and dental sealants. Community Dent Oral Epidemiol 1995;23:30-5.

15. Songpaisan $Y$, Bratthall D, Phantumvanit P, Somridhivej Y. Effects of glass ionomer cement, resin-based pit and fissure sealant and HF applications on occlusal caries in a developing country field trial. Community Dent Oral Epidemiol 1995;23:25-9.

16. Beiruti N, Frencken JE, van't Hof MA, Taifour D, van Palenstein Helderman WH. Caries-preventive effect of a one-time application of composite resin and glass ionomer sealants after 5 years. Caries Res 2006;40:52-9. 